University of Massachusetts Amherst

ScholarWorks@UMass Amherst

Chemistry Department Faculty Publication Series

Chemistry

1989

\title{
Laser Ablation System for Solid Sample Analysis by Inductively Coupled Plasma Atomic Emission Spectrometry
}

Susan A. Darke

Stephen E. Long

Christopher J. Pickford

Julian Tyson

University of Massachusetts Amherst

Follow this and additional works at: https://scholarworks.umass.edu/chem_faculty_pubs

Part of the Chemistry Commons

\section{Recommended Citation}

Darke, Susan A.; Long, Stephen E.; Pickford, Christopher J.; and Tyson, Julian, "Laser Ablation System for Solid Sample Analysis by Inductively Coupled Plasma Atomic Emission Spectrometry" (1989). Journal of Analytical Atomic Spectrometry. 1377.

Retrieved from https://scholarworks.umass.edu/chem_faculty_pubs/1377 


\title{
Laser Ablation System for Solid Sample Analysis by Inductively Coupled Plasma Atomic Emission Spectrometry*
}

\author{
Susan A. Darke, Stephen E. Longt and Christopher J. Pickford \\ Environmental and Medical Sciences Division, Harwell Laboratory, Oxfordshire OX11 ORA, UK \\ Julian F. Tyson¥ \\ Department of Chemistry, University of Technology, Loughborough, Leicestershire LE11 3TU, UK
}

\begin{abstract}
A laser ablation sample introduction system, based on a Nd: YAG laser with an $X-Y-Z$ directional sampling head, has been designed and constructed for use with inductively coupled plasma optical emission spectrometry. A study has been made of a number of parameters which affect the performance of the system to establish the optimum operating conditions. South African Reference Material (SARM) rock samples have been analysed using the system, and the results obtained have been compared with the certificate values. The importance of using closely matrix-matched samples and standards is demonstrated. Precision studies on SARM 5 (pyroxenite) show that both intra- and inter-sample precisions are typically $10 \%$ (relative standard deviation).
\end{abstract}

Keywords: Solid sampling; laser ablation; inductively coupled plasma optical emission spectrometry

The most common method used for sample introduction into an inductively coupled plasma (ICP) system is solution nebulisation. This process is considered to be performance limiting as it is inefficient. This method of sample introduction requires the sample to be in liquid form and therefore solid samples are converted into solutions before analysis. This process of dissolution may greatly increase the analysis time, dilute the analyte below the level that can be readily measured and may also increase the risk of sample contamination and loss of volatile species. Some common types of sample may suffer from these disadvantages when introduced to the ICP as solutions, hence solid sample introduction methods make attractive alternatives in these areas.

Solid sampling methods for ICP have been reviewed extensively, ${ }^{1,2}$ although none of these methods has been developed to the extent that they are in widespread routine use. The combination of vaporisation by laser ablation and excitation by the ICP is one such method of solid sample introduction. The ablated material produced by the laser is transported by a stream of argon gas to the ICP, where it can be analysed either by optical emission spectrometry (OES) ${ }^{3-6}$ or mass spectrometry (MS). ${ }^{7,8}$ Laser ablation sample introduction has been used for the determination of a range of materials including metals, ${ }^{9}$ ceramics ${ }^{10}$ and geochemical samples. ${ }^{11}$

In this paper a laser ablation system is described which has been designed for use with ICP-OES and ICP-MS instruments. A study has been made of a number of parameters which affect the performance of the system and the accuracy and precision attainable have been evaluated for geochemical reference materials by ICP-OES.

This work forms part of a continuing investigation of the relative merits of various solid sampling techniques for the ICP, including slurry nebulisation and electrothermal vaporisation (ETV) of solids. These methods are being considered as possible alternatives to solution nebulisation for samples that prove difficult to dissolve. One overall aim of the work is to try and overcome the disadvantages associated with solid

* Presented at the Fourth Biennial National Atomic Spectroscopy Symposium (BNASS), York, UK, 29th June-1st July, 1988.

$\dagger$ Present address: Technology Applications, US Environmental Protection Agency, Cincinnati, OH 45219, USA.

\pm To whom correspondence should be addressed. Present address: Department of Chemistry, Lederle Graduate Research Tower A, University of Massachusetts, Amherst, MA 01003, USA. sample introduction techniques, ${ }^{12}$ particularly those associated with calibration and obtaining homogeneous, representative samples.

\section{Experimental}

\section{Apparatus}

A Spectron Laser Systems (Rugby, Warwickshire, UK) Nd: YAG laser, Model SL402, was used in this work. It was operated in the free running mode, with a fixed pulse length of $200 \mu \mathrm{s}$. The laser has two possible ranges of energy output, i.e., the "multimode" $(1.0-2.0 \mathrm{~J})$ and the "single transverse mode" $\left(\mathrm{TEM}_{00}\right)(0.1-0.2 \mathrm{~J})$. An $X-Y-Z$ directional sampling head allowed the sample to be moved in three dimensions with respect to the focused laser beam. The position of focus was accurately located by an infrared beam and detector. The cell assembly is shown in more detail in Fig. 1. The sample cell was constructed from a cylindrical glass tube of $35 \mathrm{~mm}$ internal diameter and $80 \mathrm{~mm}$ high, with tangential arms for gas inlet and outlet. The plate-glass cell cover was angled at $45^{\circ}$ to eliminate reflections within the objective lens. The base was made of PTFE, and was constructed with an O-ring seal to allow easy removal for sample changing. A three-way tap is incorporated into the system to allow the argon flow to the ICP to by-pass the sample chamber during sample changeover to prevent the plasma being extinguished. The entire head assembly was enclosed in a steel box with interlocking door to prevent emission of reflected laser energy into the laboratory.

A Plasma-Therm (Kresson, NJ, USA) ICP source unit was used when optimising the system for ICP-OES work, and to study the effect of changing various parameters upon system performance. The ICP consisted of an HFP-2500D r.f. generator $(27.12 \mathrm{MHz})$ and a Model 2500 plasma torch assembly. The spectrometer used was a Spex (Metuchen, NJ, USA) Model $17041-\mathrm{m}$ focal length scanning monochromator fitted with a Czerny-Turner mounting and a holographic grating ruled with 2400 lines $\mathrm{mm}^{-1}$ with entrance and exit slits set at 35 and $30 \mu \mathrm{m}$, respectively. This, together with a Spex DPC-2 digital photometer and a Spectra-Physics (San Jose, CA, USA) SP4290 HPLC integrator were used for data collection and display. An ARL 3560 (Applied Research Laboratories, Crawley, Sussex, UK) simultaneous ICP-OES instrument was used for the analytical measurements on geochemical samples. The instrumental settings given in Table 1 were used for this part of the study. Table 2 shows the wavelengths used for the simultaneous ICP-OES work. 


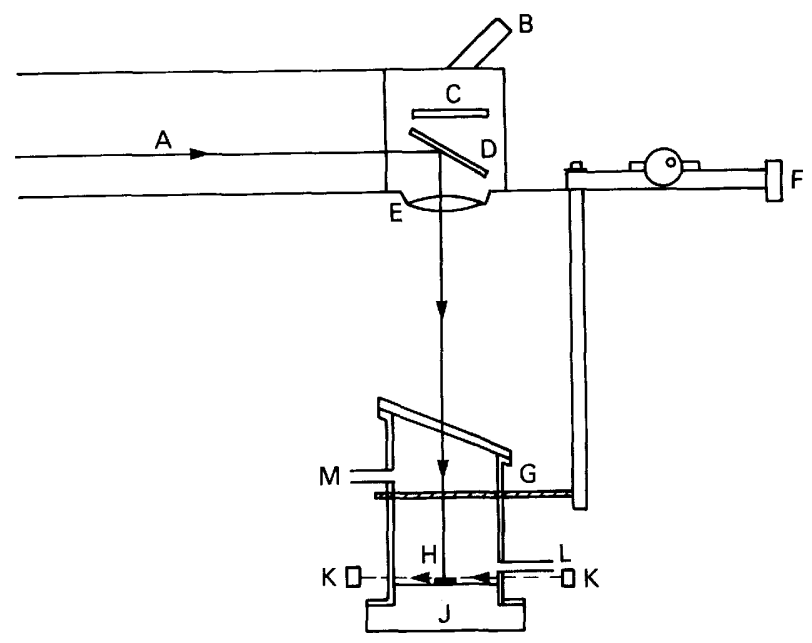

Fig. 1. Schematic diagram of the cell assembly used with the laser ablation system. A, Laser beam direction; B, binocular viewing head; $C$, viewing filter; $D$, steeing mirror mount; $E$, objective lens (focal length $=150 \mathrm{~mm}$ ); F, $X \cdot Y-Z$ directional sampling head; $\mathrm{G}$, sample cell and holder; H. sample; J, PTFE base; K, IR beam and detector; $\mathrm{L}$, argon inlet; and $\mathrm{M}$ argon outlet to ICP

Table 1. Instrument settings for the ARL 3560 ICP-OES instrument used for geochemical analysis

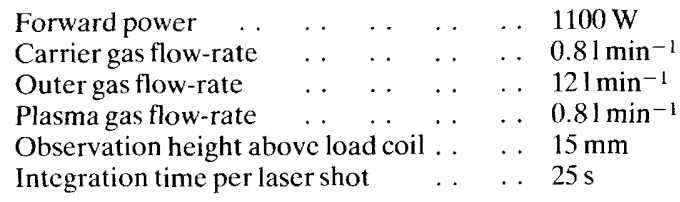

Table 2. Wavelengths used for ICP-OES instrument measurements of the geochemical samples

\begin{tabular}{|c|c|c|c|c|c|}
\hline & Element & & Atom/ion line & Wavelength/nm & Order \\
\hline $\mathrm{Al}$ & . . & . & I & 308.2 & 2 \\
\hline $\mathrm{Ba}$ & $\ldots$ & $\cdots$ & II & 493.3 & 1 \\
\hline $\mathrm{Ca}$ & $\ldots$ & $\ldots$ & II & 315.9 & 2 \\
\hline In & . & . & II & 230.6 & 2 \\
\hline K & . & . & I & 766.4 & 1 \\
\hline $\mathrm{Mn}$ & . & . & II & 257.6 & 3 \\
\hline $\mathrm{Na}$ & $\ldots$ & . & I & 589.0 & 1 \\
\hline $\mathrm{Si}$ & $\ldots$ & $\ldots$ & I & 288.1 & 2 \\
\hline $\mathrm{Sr}$ & . & . & Il & 407.7 & 1 \\
\hline $\mathrm{Ti}$ & . & . & II & 337.2 & 2 \\
\hline $\mathrm{Y}$ & . & . & II & 371.0 & 2 \\
\hline
\end{tabular}

\section{Sample Preparation}

A number of binding materials including methyl methacrylate, cellulose and Mowiol [poly(vinyl alcohol), Hoechst UK, Hounslow, Middlesex, UK] were evaluated. Mowiol was chosen for use as it could be added at low concentrations and hence reduce the risk of contamination from the binding material. The powdered rock samples were used as supplied, i.e., in a form in which $98 \%$ of the material passed through a sieve with an aperture size of $75 \mu \mathrm{m}$. A sub-sample was taken and dried in an oven at $105^{\circ} \mathrm{C}$ until a constant mass was reached. Approximately $2 \mathrm{~g}$, weighed accurately, was then taken. To produce a pellet suitable for ablation, the dried powdered samples were mixed manually with a $1 \% \mathrm{~m} / \mathrm{V}$ solution of Mowiol in distilled water, a 1-ml aliquot of which was added to $1 \mathrm{~g}$ of sample. Yttrium and indium were added at the $100 \mathrm{ug} \mathrm{g}^{-1}$ level as internal standards. They were added as $1000 \mathrm{ug} \mathrm{ml}^{-1}$ in-house standard solutions together with the binding material. Two internal standards were used to allow closer matching between the standard and the analyte element. An atom line and an ion line are usually selected, for example, Sc II $255.3 \mathrm{~nm}$ and Sc I $402.0 \mathrm{~nm},{ }^{13}$ but these lines

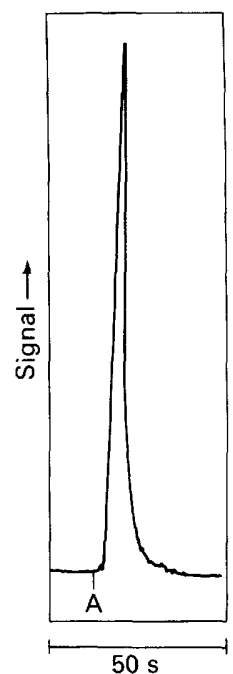

Fig. 2. A typical transient signal for laser ablation ICP-OES. Laser fired at point $A$

Table 3. Examples of laser energy used

Sample Laser energy/mJ

$\begin{array}{llllll}\mathrm{ZrO}_{2} \text { (pressed powder) } \ldots & \ldots & \ldots & \ldots & 100\end{array}$

$\begin{array}{llllll}\mathrm{TiO}_{2} \text { (pressed powder) } & \ldots & \ldots & \ldots & \ldots & 130\end{array}$

$\begin{array}{llllllll}\text { Mild steel } & \ldots & \ldots & \ldots & \ldots & \ldots & \ldots & 1600\end{array}$

Brass. .1600

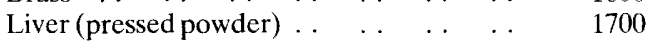

were not available on the polychromator array of the ARL 3560 spectrometer used in this work. The In II 230.6-nm and Y II 371.0-nm lines, high- and low-excitation energy lines, respectively, were used. Neither of these elements are of any importance in geochemical analysis, however, they are used in arc spectrometry as internal references. The samples were dried in a desiccator or in an oven at $50{ }^{\circ} \mathrm{C}$ and the resulting material was reground before pressing into a pellet in a $1.5-\mathrm{cm}$ die at 10 tons pressure. The reference materials used in the geochemical analyses were South African Reference Materials (SARMs) 1 (granite), 2 (syenite), 4 (norite) and 5 (pyroxenite), (South African Bureau of Standards, Pretoria, South Africa).

\section{Procedures}

A study was made of a number of parameters which affected the performance of the system including carrier gas flow-rate, laser pulse energy, connection tube length and transport efficiency. The accuracy and precision attainable with the system were evaluated using conditions selected from this study.

\section{Results and Discussion}

Study of the Operating Parameters for the Laser Ablation System

An investigation of the operating parameters for the laser ablation system was carried out using the Plasma-Therm ICP and Spex monochromator, adopting a univariate approach. Initially, a mild steel sample of known composition was ablated repeatedly using single pulses. A typical response to a single pulse is shown in Fig. 2. The laser energy selected for the mild steel sample was $1.7 \mathrm{~J}$, but it varied for different sample materials depending on their physical properties (Table 3). The amount of sample removed per shot was used to decide the laser energy used. The response of the $\mathrm{Cu}$ I 327.396-nm, Cr II 285.568-nm and Mn I 279.482-nm lines was 

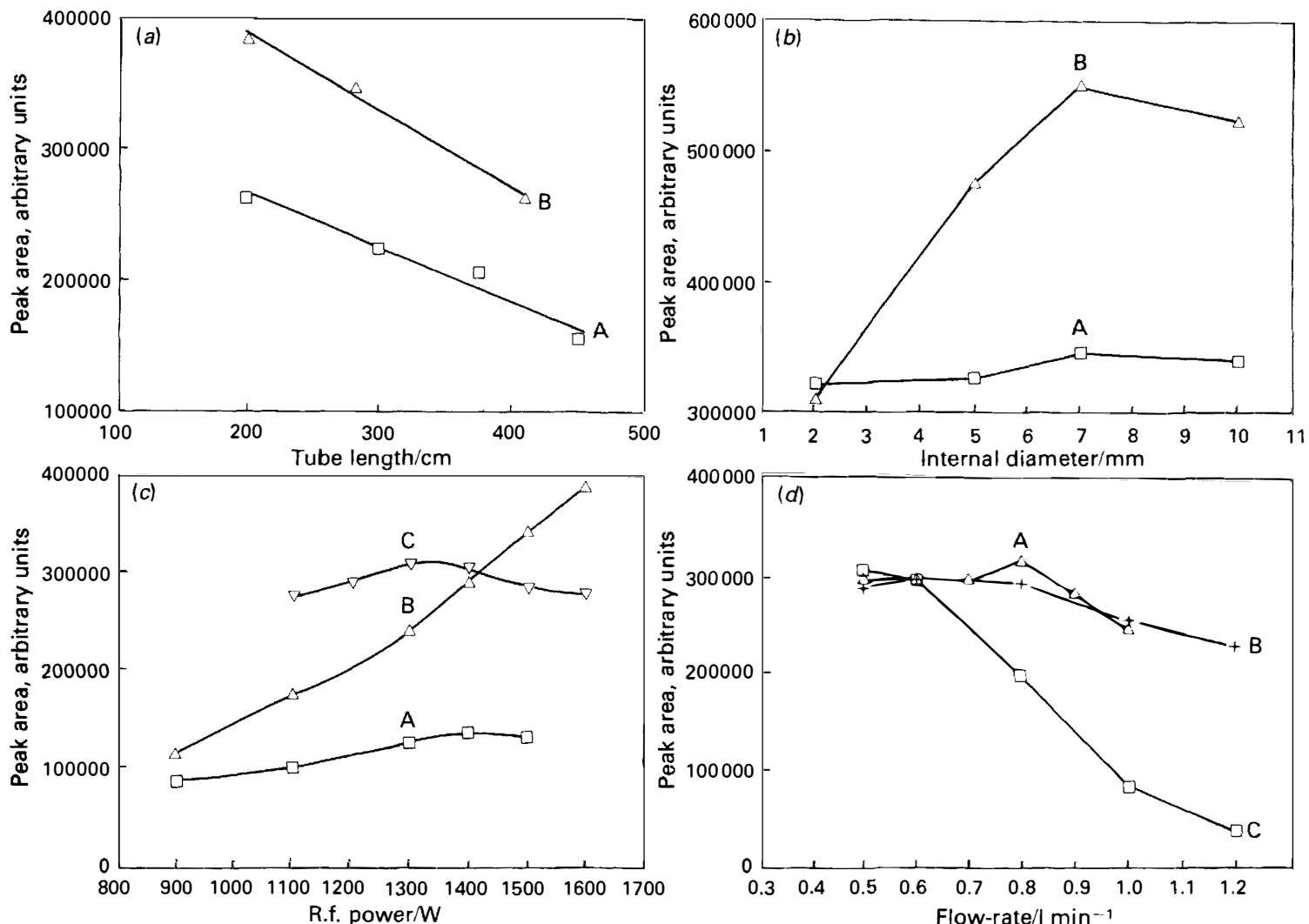

Fig. 3. Plots of the variation of operating parameters for the laser ablation system. (a) Effect of varying tube length, $(b)$ effect of varying internal diameter and $(c)$ effect of varying r.f. power; $\mathrm{A}$, copper, $\mathrm{B}$, chromium and $\mathrm{C}$, manganese. (Carrier gas flow-rate. 0.8 $1 \mathrm{~min}^{-1}$.) $(d)$ Effect of varying carrier gas flow-rate: A, Mn I $279.98 \mathrm{~nm} ; \mathrm{B}$, Cu I $327.39 \mathrm{~nm}$; and C, Cr II 285.57 nm (r.f. power, $1500 \mathrm{~W}$ )

Table 4. Optimum conditions for the laser ablation ICP-OES system

$\begin{array}{llll}\text { Connection tube length . . } \ldots & \ldots & \ldots & 200 \mathrm{~cm} \\ \text { Connection tube internal diameter } & \ldots & \ldots & 7 \mathrm{~mm} \\ \text { Carrier gas flow-rate for "soft line" } \ldots & \ldots & 0.81 \mathrm{~min}^{-1} \\ \text { Carrier gas flow-rate for "hard line" } & \ldots & 0.61 \mathrm{~min}^{-1}\end{array}$

Table 5. Laser ablation ICP-OES analysis of SARM 5

Measured concentration*, \%

$\begin{array}{ccc}\begin{array}{c}\text { Calibrated } \\ \text { with SARM } 2\end{array} & \begin{array}{c}\text { Calibrated } \\ \text { with SARM 4 }\end{array} & \begin{array}{c}\text { Certificate } \\ \text { value, \% }\end{array} \\ 3.80(0.47) & 2.30(0.28) & 2.2 \\ 0.30(0.01) & 0.14(0.006) & 0.07 \\ 0.23(0.02) & 0.33(0.03) & 0.27 \\ 36.0(1.4) & 21.0(0.82) & 24.0\end{array}$

Measured concentration $* / \mu g^{-1}$

Calibrated Calibrated Certificatet with SARM 2 with SARM 4 value/ $\mu \mathrm{gg}^{-1}$

$\begin{array}{llllrcrr}\mathrm{Ba} & \ldots & \ldots & \ldots & 88.0 & (7.20) & 59(4.8) & 46 \\ \mathrm{Mn} & \ldots & \ldots & \ldots & 820 & (14.0) & 1710(29) & 1700 \\ \mathrm{Sr} & \ldots & \ldots & \ldots & 22 & (3.1) & 27.0(3.6) & 32 \\ \mathrm{Ti} & \ldots & \ldots & \ldots & 870 & (87) & 1090(110) & 1200\end{array}$

* Standard deviations in parentheses. Number of replicates 4 .

$\div$ Certificate of Analysis, NIM-P. Pyroxenite SARM 5. SA Bureau of Standards, Pretoria. South Africa.

observed on changing the carrier gas flow-rate, r.f. power of the plasma and connecting tube length and internal diameter. Fig. 3(a) $-(\boldsymbol{d})$ shows the results of these experiments. From these results the conditions necessary for "hard" and "soft" 14,15 emission lines can be derived (Table 4) under fixed viewing height. It was found that flow-rates of 0.8 and 0.6 $1 \min ^{-1}$ gave the maximum response and best signal to
Table 6. Certificate concentrations for SARMs used for geochemical analysis

Certified value*

\begin{tabular}{|c|c|c|c|c|}
\hline Constituent & SARM 1 & SARM 2 & SARM 4 & SARM 5 \\
\hline $\mathrm{SiO}_{2}, \% \quad \ldots$ & 75.70 & 63.63 & 52.64 & 51.1 \\
\hline $\mathrm{Al}_{2} \mathrm{O}_{3}, \% \ldots$ & 12.0 & 17. & 16.5 & \\
\hline $\mathrm{Na}_{2} \mathrm{O}, \% \ldots$ & 3.36 & 0.43 & 2.46 & 0.37 \\
\hline $\mathrm{K}_{2} \mathrm{O}, \%$ & 4.99 & 15.35 & 0.25 & 0.09 \\
\hline $\begin{array}{l}\text { Total } \mathrm{Fe} \text { as- } \\
\mathrm{Fe}_{2} \mathrm{O}_{3}, \% \ldots\end{array}$ & & & & \\
\hline $\begin{array}{l}\mathrm{Fe}_{2} \mathrm{O}_{3}, \% \quad \ldots \\
\mathrm{MgO}, \% \quad \ldots\end{array}$ & $\begin{array}{l}2.00 \\
0.06\end{array}$ & $\begin{array}{l}1.4 \\
0.4\end{array}$ & $\begin{array}{l}8.97 \\
7.50\end{array}$ & $\begin{array}{l}12.70 \\
25.33\end{array}$ \\
\hline $\mathrm{CaO}, \%$ & 0.78 & 0.68 & 11.50 & 2.66 \\
\hline $\mathrm{Sr} / \mu \mathrm{gg}^{-1}$ & 62 & & 32 & \\
\hline $\mathrm{MnO}$ & $207 \mu \mathrm{g} \mathrm{g}^{-1}$ & $103 \mu \mathrm{g} \mathrm{g}^{-1}$ & $0.18 \%$ & 0.22 \\
\hline $\mathrm{TiO}_{2}$ & $901 \mu \mathrm{g} \mathrm{g}^{-1}$ & $442 \mu \mathrm{g} \mathrm{g}^{-1}$ & $0.20 \%$ & 0.20 \\
\hline & $\ldots 120 \mu \mathrm{g} \mathrm{g}^{-1 \dagger}$ & $0.24 \%$ & $102 \mu \mathrm{g} \mathrm{g}^{-1}$ & $46 \mu \mathrm{gg}$ \\
\hline
\end{tabular}

* Certificate of Analysis, SA Bureau of Standards, Pretoria, South Africa, uncertainties are not listed for these elements.

$\dagger$ Uncertified value from Certificate of Analysis.

background and signal to noise ratio conditions for "soft" and "hard" lines, respectively. The connection tubing results showed the same trend for both types of emission line; a piece of tubing $200 \mathrm{~cm}$ in length and with an internal diameter of 7 $\mathrm{mm}$ gave the maximum response and best signal to background ratio. This was the minimum practical length possible, in the system used, due to the position of the torch box on the bench.

Transport efficiency was measured, under conditions selected from the above results, by collecting the ablated material in a tube packed with silica wool. The tube was placed downstream of the cell in the position normally occupied by the ICP torch. Copper oxide compressed into pellets was used 
as the sample because it is a simple matrix which can be dissolved easily after collection. Ablated material was then collected in the tube after 100 shots. The material trapped in the tube was dissolved in $20 \% \mathrm{~V} / \mathrm{V}$ nitric acid and the total mass of copper determined by ICP-OES. The total mass of material ablated was determined by accurately weighing the sample before and after the ablation process. Under these conditions, the transport efficiency for copper was calculated to be $40 \%$. A similar laser ablation transport efficiency measurement has been made by Arrowsmith and Hughes for Mo. ${ }^{16}$

A compromise set of conditions was selected for simultaneous analysis (Table 1), some of the parameters varying from those that would have been chosen from the results shown above. For example, r.f. power was $1100 \mathrm{~W}$, due to the limited range available with the ICP-OES instrument used. The number of replicate shots is not necessarily the optimised value and further work is needed in this area.

\section{Laser Ablation ICP-OES Measurements}

A range of major and minor elements was determined in SARM 5 using the ARL 3560 spectrometer, SARM 2 and SARM 4 were used for calibration, using the internal standards yttrium and indium to correct for any inter-sample ablation effects. Use of internal standardisation produced a maximum change of $10 \%$ in measured concentrations: in practice it produced no significant improvement either in precision or accuracy. The effect of using closely matrixmatched standards is illustrated by the data in Table 5 . The reference SARM 4 is of similar elemental composition to SARM 5, whereas SARM 2 contains a high concentration of potassium compared with the other two standards (see Table

Table 7. Laser ablation ICP-OES analysis of SARM 2

\begin{tabular}{|c|c|c|c|c|}
\hline & Element & & $\begin{array}{c}\text { Measured } \\
\text { concentration } \\
\text { calibrated with } \\
\text { SARM } 1 * . \%\end{array}$ & $\begin{array}{c}\text { Certificate } \\
\text { value, } \%\end{array}$ \\
\hline $\mathrm{Al}$ & $\ldots$ & . & $7.3(1.2)$ & 6.4 \\
\hline K & . . & & $17(1.2)$ & 4.1 \\
\hline $\mathrm{Na}$ & . & & $4.6(0.32)$ & 2.5 \\
\hline $\mathrm{Si}$ & $\cdots$ & 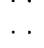 & $7.9(0.86)$ & 35.5 \\
\hline & & & $\begin{array}{c}\text { Measured } \\
\text { concentration } \\
\text { calibrated with } \\
\text { SARM } 1 / \mu g^{-1}\end{array}$ & $\begin{array}{l}\text { Certificate } \\
\text { value/ } / \mathrm{gg}^{-1}\end{array}$ \\
\hline $\mathrm{Ba}$ & . & . & $354(16.5)$ & 120 \\
\hline $\mathrm{Mn}$ & & & $117(45)$ & 160 \\
\hline $\mathrm{sr}$ & & & $22(1.0)$ & 10 \\
\hline $\mathrm{Ti}$ & $\ldots$ & 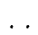 & $1190(196)$ & 540 \\
\hline
\end{tabular}

* Standard deviations given in parentheses. Number of replicates 4.

Table 8. Precision studies on SARM 5, standard deviation given in parentheses, number of replicates 5

\begin{tabular}{|c|c|c|c|c|}
\hline \multirow{2}{*}{\multicolumn{2}{|c|}{ Element }} & \multicolumn{3}{|c|}{ Concentration, $\%$} \\
\hline & & & Jnknown 1 & Unknown 2 \\
\hline $\mathrm{Al}$ & . & & $.20(0.25)$ & $2.2(0.20)$ \\
\hline $\mathrm{Ca}$ & $\ldots$ & & $.8(0.04)$ & $1.8(0.10)$ \\
\hline $\mathrm{K}$ & $\ldots$ & & $.05(0.02)$ & $0.04(0.004)$ \\
\hline $\mathrm{Mn}$ & $\ldots$ & & $.17(0.003)$ & $0.17(0.003)$ \\
\hline $\mathrm{Na}$ & $\ldots$ & & $.21(0.02)$ & $0.22(0.02)$ \\
\hline \multirow[t]{3}{*}{$\mathrm{Si}$} & $\cdots$ & 24 & $(0.88)$ & $23 \quad(0.88)$ \\
\hline & & \multicolumn{3}{|c|}{ Concentration $/ \mu g^{-1}$} \\
\hline & & & Unknown 1 & Unknøwn 2 \\
\hline $\mathrm{Ba}$ & . & . & $37(11)$ & $36(1.6)$ \\
\hline $\mathrm{Sr}$ & & & $27(3.0)$ & $27(2.4)$ \\
\hline $\mathrm{Ti}$ & . & .. & 1250 (180) & $1200(100)$ \\
\hline
\end{tabular}

6). The results reflect this similarity between SARMs 4 and 5 . The values obtained using SARM 4 for calibration more closely resemble the certificate values than do those obtained using SARM 2.

For the analysis of SARM 5, with SARM 2 as standard, it can be seen that of the four high results $(\mathrm{Al}, \mathrm{K}, \mathrm{Si}$ and $\mathrm{Ba})$, three of these are for elements for which an atom line is monitored and for the four low results ( $\mathrm{Na}, \mathrm{Mn}, \mathrm{Sr}$ and $\mathrm{Ti}$ ) three are for elements for which an ion line is monitored. This suggests that one possible explanation may be concerned with an ionisation suppression effect related to the presence of easily ionised elements. However, the materials also differ considerably in their iron content (see Table 6) which could affect the extent of the laser interaction with the sample, because the colour of the material is related to the iron content. As a further test, SARM 2 was used as a standard for the analysis of SARM 1. As can be seen from Table 6, these materials are more closely matched with respect to their iron content than with respect to their potassium content (the element most likely to be responsible for any ionisation effects). The results are shown in Table 7 from which it can be seen that enhancements were obtained for five elements $(K$, $\mathrm{Na}, \mathrm{Ba}, \mathrm{Sr}$ and $\mathrm{Ti}$ ) of which only two are elements for which an atom line was monitored. A depression was observed for $\mathrm{Si}$ which was monitored at an atom line. These results do not support the idea that the errors obtained are due to one particular phenomenon as it would appear that the factors controlling both the ablation event and the plasma characteristics are involved.

Further measurements on SARM 5 were carried out to investigate the inter- and intra-sample precision attainable with the system. Three separate pellets of SARM 5 were prepared. One was used as a standard and the other two were measured as unknowns. As can be seen from Table 8 , intra-sample relative standard deviations range from 1.8 to $40 \%$; the majority being below $10 \%$. There is good agreement between the two data sets showing that inter-sample precision is also good.

\section{Conclusions}

Using the system described, laser ablation ICP-OES can be used to make qualitative and semi-quantitative determinations of the elemental composition of geochemical samples. The precision studies on SARM 5 show that both intra- and inter-sample precisions are typically $10 \%$ when using ICPOES. Only potassium differs from this value significantly. Further studies with this technique are in progress including alternative methods of sample preparation to reduce intersample matrix effects and the use of laser ablation introduction for ICP-MS.

This work was supported by the Underlying Research Programme of the United Kingdom Atomic Energy Authority.

\section{References}

1. Zil'bershtein, Kh. I., ICP Inf. Newsl., 1985, 10, 964.

2. Darke, S. A., Long, S. E., and Tyson, J. F., Rep. UK Atom. Energy Auth., AERE-R12812, HM Stationery Office, London, 1987.

3. Abercrombie, F. N., Silvester, M. D., Murry, A. D., and Barringer, A. R., "Applications of Inductively Coupled Plasmas to Emission Spectroscopy," Eastern Analytical Symposium, Franklin Institute Press, PA, 1978, p. 121.

4. Thompson, M., Goulter, J. E., and Sieper, F., Analyst, 1981, 106, 32 .

5. Carr, J. W., and Horlick, G., Spectrochim. Acta, Part B, 1982 , 37, 1

6. Ishizuka, T., and Uwamino, Y., Spectrochim. Acta, Part B, $1983,38,519$.

7. Gray, A. L., Analyst, 1985, $110,551$.

8. Arrowsmith, P., Anal. Chem., 1987, 59, 1437. 
9. Kawaguchi. H., Xu. J., Tanaka, T., and Mizuike. A., Bunseki Kagaku, 1982, 31, E185.

10. "Technical Information PQ709A." VG Isotopes, Elemental Division, Winsford, Cheshire, 1987.

11. Hale. M., and Thompson, M., Trans. Inst. Min. Metall, Sect. B. 1983, 92, 23.

12. Sneddon. J., Spectroscopy, 1986, 1. 34.

13. Watson, A. E., and Russell, G. M., ICP Inf. Newsl., 1979, 4 , 441.
14. Boumans, P. W. J. M., ICP Inf. Newsl., 1978, 4, 89

15. Blades, M. W., and Horlick, G., Spectrochim. Acta, Part B, 1981, 36, 361.

16. Arrowsmith, P., and Hughes. S. K., Appl. Spectrosc., 1988, 42. 1231.

Paper $8 / 04753 G$

Received November 30th, 1988 Accepted August 25th, 1989 